\title{
(6) IQOS campaign in Israel
}

\section{OPEN ACCESS}

'Department of Health Promotion, School of Public Health, Sackler Faculty of Medicine, Tel Aviv University, Ramat Aviv, Israel

${ }^{2}$ The National Initiative to Eradicate Smoking (Smoke-Free Israel), Ramat Raziel, Israel

Correspondence to Dr Laura J Rosen, Department of Health Promotion, School of Public Health, Tel Aviv University, Ramat Aviv 69978, Israel; rosenl@post.tau.ac.il

Received 9 July 2018

Revised 14 September 2018

Accepted 17 September 2018

Check for updates

(C) Author(s) (or their employer(s)) 2018. Re-use permitted under CC BY-NC. No commercial re-use. See rights and permissions. Published by BMJ.

To cite: Rosen LJ, Kislev S. Tob Control

2018:27:578-581.

\section{INTRODUCTION}

At present, IQOS, Philip Morris's (PM's) heated tobacco product, is being test-marketed in 30 countries worldwide. ${ }^{1}$ Similarly to electronic cigarettes, ${ }^{2}$ regulation varies widely by country. In the USA, for example, sales and marketing of IQOS are currently prohibited by the Food and Drug Administration's (FDA's) premarket approval structure, pending a decision by the FDA. ${ }^{3}$ Canada allows marketing, and has been termed a 'dark market' due to its strong tobacco advertising ban in combination with its categorisation of IQOS as a tobacco product. ${ }^{4}$ Italy, by contrast, has exempted IQOS from its comprehensive ban on cigarette advertising and also from the graphic warnings which are required on cigarettes. ${ }^{5}$

This paper describes the entry of IQOS into Israel, and its marketing campaign (see Figure 1). In 2016, when the IQOS campaign began, the adult smoking prevalence was $21.6 \% .^{6}$ Israel was a signatory to the Framework Convention on Tobacco Control (FCTC), had a governmentally approved tobacco control plan, national legislation for smoke-free public indoor and outdoor places and high levels of taxation. ${ }^{7}$ A partial advertising ban was in place which prohibited advertisement of tobacco products on television and radio, and in print press publications directed at youth. ${ }^{7}$ No premarket regulatory mechanism existed for any tobacco or nicotine product, and Israel did not have any distinct category for emerging tobacco and nicotine products.

During the first half of 2016, PM communicated directly with officials from the Ministries of Health and Finance via high-level meetings and letters prior to marketing of IQOS to the public. ${ }^{6}$ This is consistent with PM's global strategy. ${ }^{8}$ Following these meetings, the Ministry of Health $(\mathrm{MOH})$ sent a letter to the Tax Authority defining IQOS as a new product which did not fall under existing tobacco regulation. ${ }^{9}$ PM began advertising IQOS online in December 2016. In January 2017, online sales began, and in February 2017, retail sales began. Initially, the cost was about US\$100 for IQOS plus 10 packs of HEETs (HEETS, or Heat Sticks, are the cigarette-like product inserted into the IQOS holder)

The classification of IQOS as a product not subject to existing tobacco legislation was challenged in the Supreme Court with three petitions. The first petition, filed on 12 March 2017 by Dubek, a local tobacco company, demanded that IQOS be defined as a tobacco product, with taxation equal to that on cigarettes. ${ }^{10}$ The second petition was filed on 19 March 2017 by the Israel Association for Progressive Democracy, and also demanded that IQOS be defined as a tobacco product, subject to existing regulations on tobacco products. ${ }^{11}$ The Supreme Court then requested clarification from the $\mathrm{MOH}$ regarding IQOS's status. On 2 April 2017, the MOH responded that IQOS should be regulated under existing tobacco legislation, as requested by the petitioners. The third petition was filed on 15 November 2017 by two advocacy organisations: The Israel Association for a Progressive Democracy and the National Initiative to Eradicate Smoking (Smoke Free Israel). They demanded that the Minister of Finance sign the bill to tax IQOS. ${ }^{12}$ On 17 January 2018, the Minister of Finance signed the tax order for IQOS, and on 13 March 2018, following an 83-0 vote in the plenary of the Knesset, IQOS was taxed at the same rate as cigarettes. ${ }^{13}$

\section{THE IQOS MARKETING CAMPAIGN}

We observed five distinct advertising elements which were used in two separate campaigns, one for policy-makers, and another for the public. Examples of the advertisements are shown in figure 2A-F.

\section{The five campaign elements}

1. PM's 'Smoke-free Israel Vision' embodied the main concept of the entire campaign and was part of PM's global campaign for a Smoke-Free World. ${ }^{14}$ It framed the emerging tobacco and nicotine products as being fundamentally different from the combusted cigarette and promoted the idea that PM was taking a global leadership role in pursuing a world without smoke (figure 2A).

2. The harm-reduction element focused on transitioning smokers from combustible to non-combustible products. The claim that non-combustible products were risk-reduced compared with cigarettes appeared as part of this element. PM referred to the harmful chemicals in cigarette smoke as the main cause of tobacco-attributable illness, proposed alternatives and quoted from the FDA and the WHO (figure 2B). The advertisements did not state that the original WHO and FDA statements did not endorse any particular product, type of product or company in their original statements.

3. IQOS status: PM proposed that non-combustible products should enjoy a different status for the purpose of regulation due to the harm reduction (figure 2C).

4. Taxation policy: The content of messages regarding taxation policy were specific to Israel policy, though not specific to IQOS (figure 2C).

5. The classic product element was aimed at the public, and was similar to IQOS marketing elsewhere. Messages included: 'IQOS: This changes everything' (in English), TRUE (tobacco taste), 

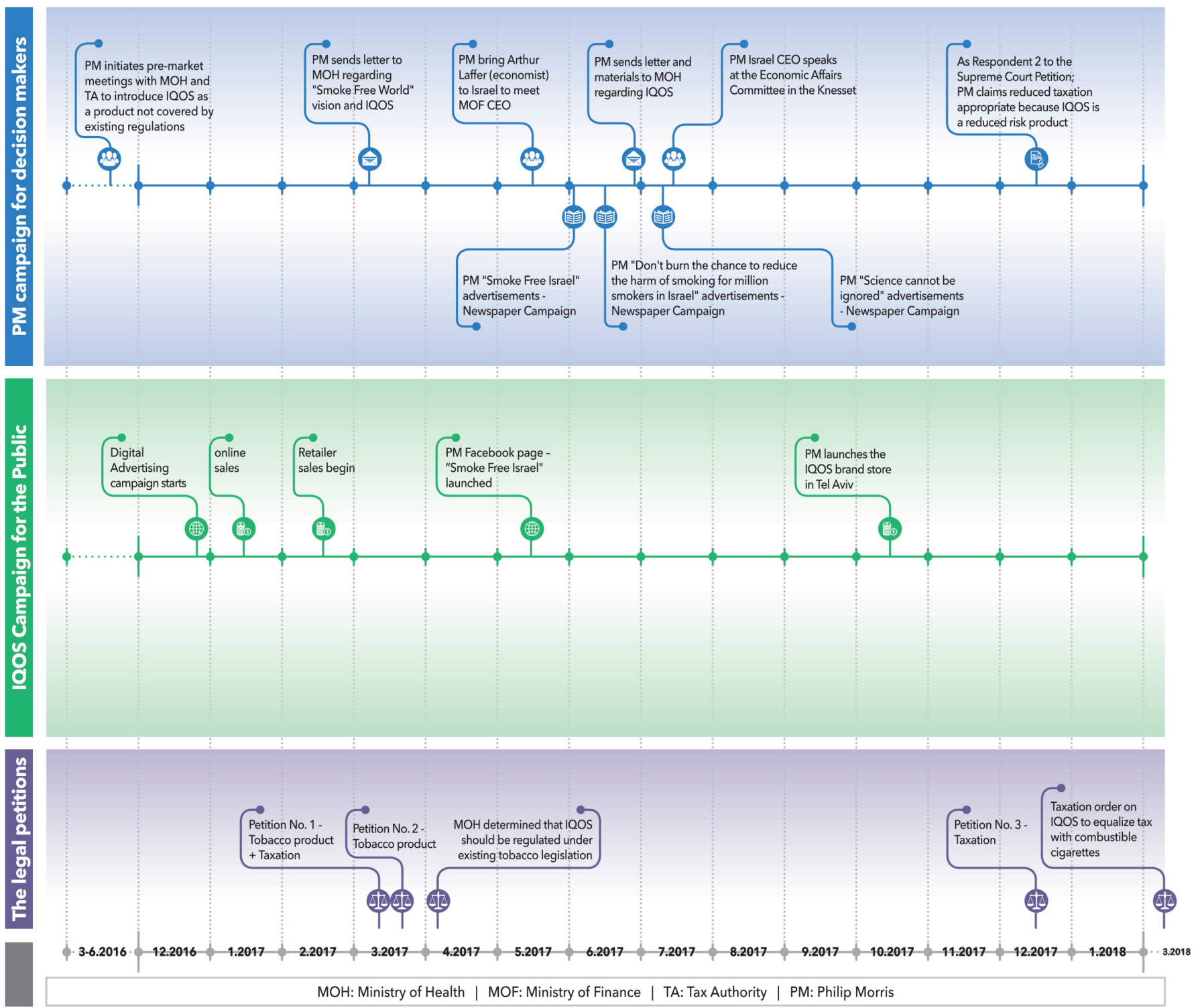

Figure 1 Timeline of IQOS campaign in Israel.

REAL (tobacco experience), 'No fire/No smoke/No ash/Less smell/Unlike cigarettes/CLEAN' (figure 2D,E,F).

\section{The two campaigns}

We observed two distinct campaigns.

The Policy Makers Campaign began with contacts between PM and governmental officials prior to advertisement or sales of IQOS to the Israeli public, and continued postmarketing. On 5 March 2017, these actions were complimented by a letter sent by $\mathrm{PM}$ to the $\mathrm{MOH}$ regarding their 'Smoke-Free World Vision' and IQOS. ${ }^{15}$ Advertisements in the print press were a key element of the campaign: these were publicised in the weekend editions of papers over many weeks, often in full or half-page advertisements. The earliest advertisements featured the SmokeFree Israel Vision (figure 2A), often with text only, without pictures and without any mention of IQOS at all. In the SmokeFree Vision ads, the PM logo was present, but not prominently. At the bottom of the advertisements were black boxed warnings. The warnings provided at the time of IQOS's launch in Israel were placed voluntarily by PM, with messages such as 'Medical researches suggest that cigarettes cause addiction' (figure 2A,D).
These advertisements used the identical style and font as governmentally required tobacco product warnings, but did not use the governmentally approved set of warnings and did not attribute them to the MOH. After IQOS's status had changed to that of a tobacco product, the black boxes included $\mathrm{MOH}$-approved warnings for cigarettes and were attributed to the $\mathrm{MOH}$.

Further actions in the campaign for decision-makers were reactive to the Supreme Court petitions and decisions. In March 2017, following the two first petitions by Dubek and the Israel Association for Progressive Democracy, PM placed large advertisements in the printed press demanding that the $\mathrm{MOH}$ 'review our science' and 'inform Israeli adult smokers about the findings in an objective and transparent manner' (figure 2B). Once IQOS was defined as a tobacco product, the battle for preferential taxation, on the basis of PM's risk-reduction argument, ensued. PM sent world-famous economist Arthur Laffer to meet with officials in the Ministry of Finance regarding taxation. ${ }^{16}$ PM further addressed the issue in well-funded print press campaigns, made possible, even after definition of IQOS as a tobacco product, by the lack of a tobacco advertising ban in the print press. The 'Don't burn the chance to reduce the harm of smoking' 

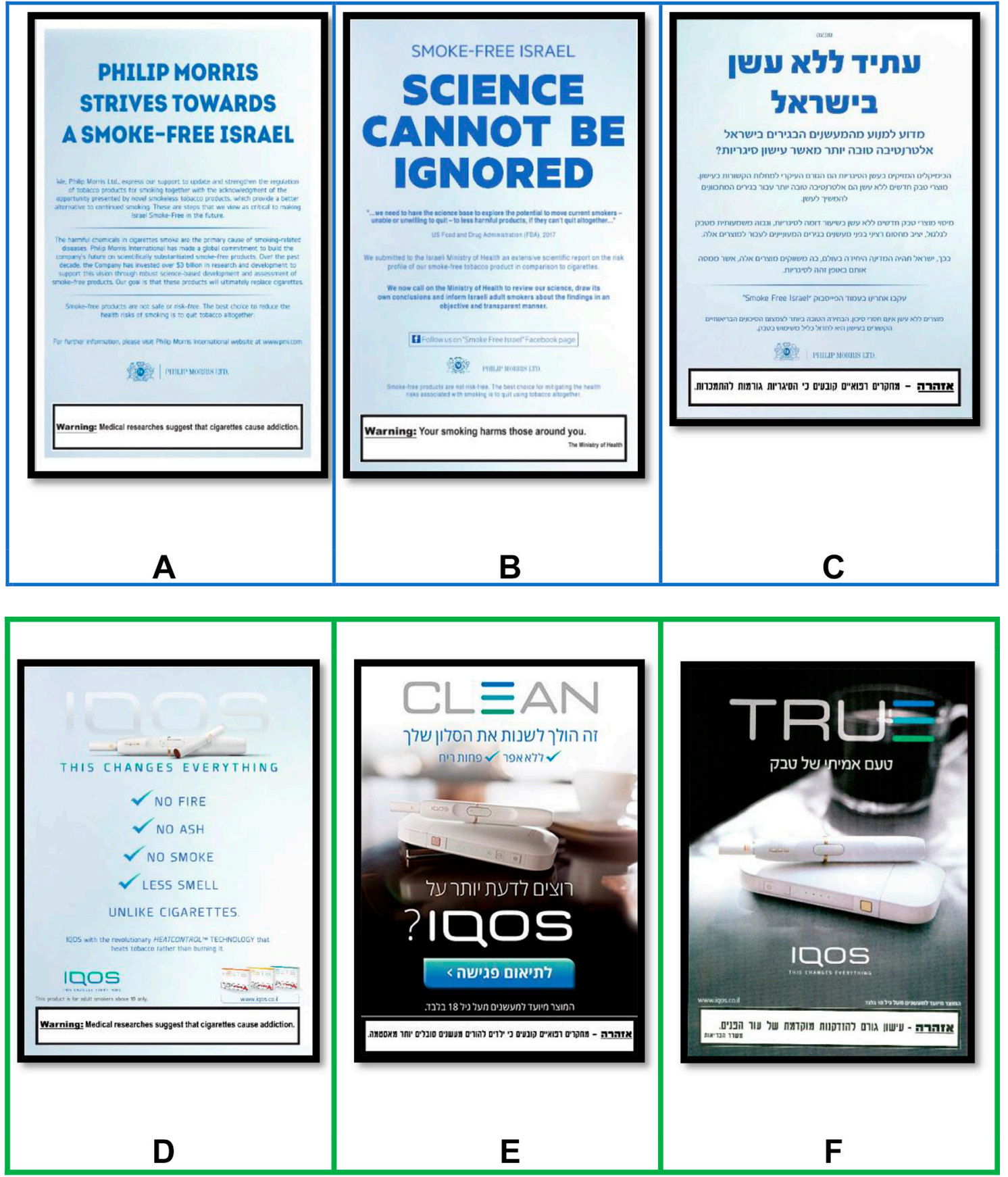

Figure 2 (A) Advertisement in English (B) Advertisement in English (C) Translation of Hebrew to English: A future without smoke in Israel. Why prevent adult smokers in Israel from having better alternatives to smoking cigarettes? The harmful chemicals in cigarette smoke are the primary cause of disease due to smoking. New smokeless tobacco products are better alternatives for smokers who plan to continue smoking. Taxation of new smokeless tobacco products at the same rate as cigarettes, at rates substantially higher than taxes on roll-your-own cigarettes, will be a serious impediment to those smokers who want to switch to these products. If this is done, Israel will be the only country in the world where these products are sold which tax them equally with cigarettes. Smoke-free products are not risk free. The best way to reduce health risks from smoking is to stop using tobacco altogether. Follow us on Facebook page Smoke Free Israel. In black box: WARNING: Medical research has shown that cigarettes lead to addiction (D) Advertisement in English (E) Translation of Hebrew to English: This is going to change your living room. No ash. Less smell. Want to know more? To schedule an appointment, press here. This product is for adult smokers $>18$ only (F) Translation of Hebrew to English: True tobacco taste. This product is for adult smokers $>18$ only. Warning: Smoking causes premature ageing of facial skin. The Ministry of Health.

advertisement, which appeared as full page ads, argued in favour of lower taxation. As the battle intensified, PM presented data in the advertisements about taxation policies in other countries, suggesting that if Israel did move to equalise taxation, it would be the only country in the world with equal taxation (figure $2 \mathrm{C}$ ).
The Public Campaign, which began with the IQOS launch, started with a widely disseminated digital marketing campaign ${ }^{17}$ which included photos of the product and short text messages. The word IQOS and the phrase 'This changes everything' appeared, in English only, on many advertisements. This differed 
from the other terms which were in Hebrew (except in advertisements in the English press, some of which are presented here). Pop-ups appeared regularly on internet sites and as people opened their smartphones or popular news websites. This was later complemented by print press advertising with similar types of messages. Other components of the campaign included a unique Facebook page under the slogan 'Smoke Free Israel' and cars with advertising messages. Package inserts advertising IQOS appeared in cigarette packages. Journalists were flown to Switzerland by PM. As an example of coverage, the report in a local English paper by a reporter flown by PM to Switzerland mentioned the words 'harm reduced' or 'less harm' 12 times in a single article, described reduced exposure to toxicants and quoted PM executives extensively. ${ }^{18}$ IQOS was also distributed to celebrities. ${ }^{1920}$ A flagship IQOS store, closely resembling Apple iPhone stores, was opened in Tel Aviv on October 2017.

\section{IMPLICATIONS}

1. In countries such as Israel, which neither require premarket approval nor have clear product definitions for emerging products, the following types of industry behaviour may occur:

a. The entry of IQOS and/or other non-combustible tobacco or nicotine products may be accompanied by campaigns aimed at both policy-makers and the public.

b. Prior to market entry, the tobacco industry may try to define emerging products as belonging to a new type of product not covered by existing tobacco laws, even if the product label clearly states that it is a tobacco product. This is particularly important if the terminology used in local laws is based on use of the term 'smoking' which PM claims is distinct from 'vaping'.

c. PM may focus on its 'smoke-free vision' which is not specific to a single product or type of product, or it may emphasise a particular product.

d. If the product is not defined as a tobacco product subject to tobacco warnings under local laws, PM may voluntarily place warnings on the product and use the identical style and font as for locally required warnings, but with messages which would not necessarily be approved by local authorities. For example, the warning stating that 'research suggests that cigarettes cause addiction' (figure $2 \mathrm{~A}, \mathrm{D})$, which was used during the IQOS campaign, may cause people to doubt the well-established evidence regarding the addictiveness of cigarettes. Introducing doubt into the public debate is consistent with the tobacco industry's previous behaviour. ${ }^{21}$

e. PM may 'change gears' during the course of the campaign, in response to regulatory proposals, in its efforts to obtain advantageous policies.

f. In countries where FCTC Article 5.3 is adhered to but there is a lack of a complete advertising ban, PM will be able to communicate directly with policy-makers through the media, even if IQOS is defined as a tobacco product.

g. In its promotional strategy, PM may selectively cite favourable policies in other countries, as well as statements made by major health organisations.

2. Because only a small minority of countries in the world have complete implementation of FCTC obligations, ${ }^{22}$ and even fewer have premarket regulation of tobacco and nicotine products, there is worldwide vulnerability to poorly regulated industry marketing, advertisement and promotion of non-combustible tobacco and nicotine products. The absence of comprehensive, enforced marketing bans on all tobacco and nicotine products, which include digital and social media, and restrictions on health claims, are specific areas of vulnerability.

Contributors LJR and SK jointly conceived of this paper, and wrote the paper together. Both authors approved the final version of the paper.

Funding The authors have not declared a specific grant for this research from any funding agency in the public, commercial or not-for-profit sectors.

Competing interests None declared.

Patient consent Not required.

Provenance and peer review Not commissioned; externally peer reviewed.

Open access This is an open access article distributed in accordance with the Creative Commons Attribution Non Commercial (CC BY-NC 4.0) license, which permits others to distribute, remix, adapt, build upon this work non-commercially, and license their derivative works on different terms, provided the original work is properly cited, appropriate credit is given, any changes made indicated, and the use is non-commercial. See: http://creativecommons.org/licenses/by-nc/4.0/.

\section{REFERENCES}

1 Hair EC, Bennett M, Sheen E, et al. Examining perceptions about IQOS heated tobacco product: consumer studies in Japan and Switzerland. Tob Control 2018;27(Suppl1):s70-s73.

2 Kennedy RD, Awopegba A, De León E, et al. Global approaches to regulating electronic cigarettes. Tob Control 2017;26:440-5.

3 Lempert L, Glantz SA. Heated tobacco product regulation under US law and the FCTC. Tob Control 2018;27(Suppl1):s118-s125.

4 Mathers A, Schwartz R, O'Connor S, et al. Marketing IQOS in a dark market. Tob Control 2018:tobaccocontrol-2017-054216.

5 Liu X, Lugo A, Spizzichino L, et al. Heat-not-burn tobacco products: concerns from the Italian experience. Tob Control 2018:tobaccocontrol-2017-054054.

6 Israel Ministry of Health. Health Minister's Report to the Knesset on Smoking (Revised), 2016. Jerusalem: Public Health Services, 2018

7 Rosen LJ, Peled-Raz M. Tobacco policy in Israel: 1948-2014 and beyond. Isr J Health Policy Res 2015;4:12

8 Bialous SA, Glantz SA. Heated tobacco products: another tobacco industry global strategy to slow progress in tobacco control. Tob Control 2018;27(Suppl1):s111-s117.

9 Grotto I. Letter: Philip Morris's alternative smoking product. Recipient: Iris Saadon, Tax Authority, 2016.

10 Israel High Court of Justice. HCoJ 2269/17 Dubek v. Minister of Health. (accessed 12 Mar 2017).

11 Israel High Court of Justice. HCoJ 2475/17 The Israel Association for Progressive Democracy v. Minister of Health. (accessed 19 Mar 2017).

12 Israel High Court of Justice. HCoJ 8929/17 The Israel Association for Progressive Democracy v. Minister of Finance (accessed 15 Nov 2017).

13 Israel Ministry of Health. Health Minister's Report on Smoking, 2017. Jerusalem, Israel, 2018.

14 Philip Morris International, 2018. Designing a smoke-free future https://www.pm com/who-we-are/designing-a-smoke-free-future.

15 Elfin D. Philip Morris International. Letter from Philip Morris to the Minister of Health. 2017.

16 Ganz RL. Economic Guru visiting Israel meets with government officials - Lobbyist of the tobacco giant Philip Morris. The Marker 2017.

17 Linder Ganz R. In the papers, in the digital media, and in the field: Philip Morris poured millions of shekels into advertising IQOS in Israel. Haaretz 2018.

18 Bob YJ. The IQOS gamble: Philip Morris's state-of-the-art research facility could revolutionize the smoking industry. Jerusalem Post 2018.

19 Spector D. Mommy, you don't stink anymore. 2016, https://www.yediot.co.il/articles/ 0,7340,L-4893716,00.html (accessed 5 Sep 2018).

20 Avri Gilad shows how to use IQOS 2017. https://www.youtube.com/watch?v= 2dd6xmmi59s. accessed 5 Sep 2018.

21 Michaels D. Doubt is their product: How industry's assault on science threatens your health: Oxford University Press, 2008.

22 World Health Organization, 2017. WHO report on the global tobacco epidemic 2017: Monitoring tobacco use and prevention policies http://www.who.int/tobacco/global_ report/2017/en/ (accessed 9 Sep 2018). 